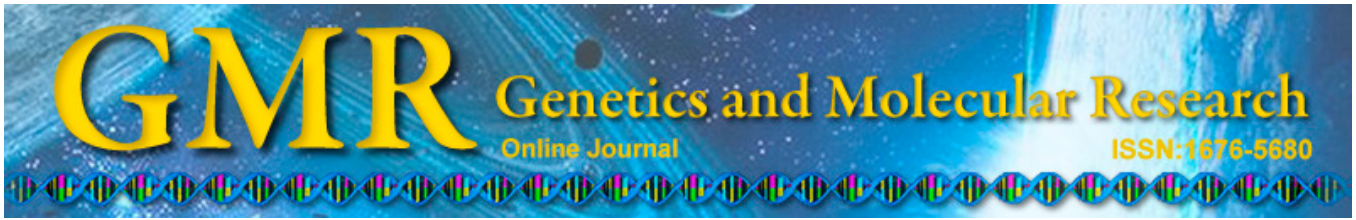

\title{
Relevance of sampling and DNA extraction techniques for the analysis of salivary evidence from bite marks: a case report
}

\author{
M.L. Chávez-Briones ${ }^{1,2}$, R. Hernández-Cortés ${ }^{2}$, G. Jaramillo-Rangel ${ }^{1}$ and \\ M. Ortega-Martínez ${ }^{1}$ \\ ${ }^{1}$ Department of Pathology, School of Medicine, \\ Autonomous University of Nuevo Leon, Monterrey, Nuevo Leon, Mexico \\ ${ }^{2}$ Forensic Genetics Laboratory, \\ Office of the General Prosecutor of the State of Nuevo Leon, \\ Monterrey, Nuevo Leon, Mexico \\ Corresponding author: M. Ortega-Martínez \\ E-mail: martaortega69@yahoo.com.mx
}

Genet. Mol. Res. 14 (3): 10165-10171 (2015)

Received March 31, 2015

Accepted May 26, 2015

Published August 21, 2015

DOI http://dx.doi.org/10.4238/2015.August.21.23

\begin{abstract}
Bite mark evidence has been repeatedly found in criminal cases. Physical comparison of a bite mark to the teeth of available suspects may not always be possible. Experimental studies have shown that the analysis of DNA present in the saliva recovered from bite marks might help in the identification of individuals. However, the application of this approach to an actual criminal case has been reported only once before in forensic literature. Therefore, there is very limited scientific and technical information available on this subject. The current study focuses on a woman found dead in her home; the autopsy ruled the death to be a result of manual strangulation. A bite mark was found on each breast. The single swab technique was used to collect evidence from these bite marks, and an organic extraction method was employed for DNA isolation. Short tandem repeat (STR) sequence typing was performed using a commercially available kit, and
\end{abstract}


the result was compared to the STR profile of a suspect. A full singlesource STR profile was obtained from both bite marks, which matched the STR profile of the suspect. To the best of our knowledge, this is the second report on the analysis of DNA isolated from bite marks on the victim used to identify the crime perpetrator. Our results indicated that, contrary to most theoretical indications, a single swab technique for evidence collection and an organic method for DNA isolation could be very useful in solving this class of criminal cases.

Key words: Bite mark; DNA typing; Saliva

\section{INTRODUCTION}

In violent crimes, offenders are known to bite their victims as an expression of dominance, rage, or animalistic behavior. The resulting physical evidence can be compared with the teeth of any suspects in order to determine the origin of the marks. The use of bite mark evidence in criminal or abuse cases has been accepted by law enforcement agencies and courts since many years (Sweet and Pretty, 2001; Bruce-Chwatt, 2010).

However, most forensic dentists have not agreed on a standard explanation regarding the individuality (uniqueness) of the dentition, or the behavior of human skin upon being bitten. Furthermore, distortions may modify, complicate, or render impossible the interpretation of a bite mark (Bowers, 2006; Pretty, 2006, 2008). The use of bite marks as forensic evidence has an average false-positive error of $64 \%$ (Saks and Koehler, 2005). These difficulties have resulted in the use of salivary DNA evidence, deposited during the biting action, for the definitive identification of the perpetrator of the bite.

Studies conducted under controlled laboratory conditions have indicated that the DNA analysis of saliva placed on the skin of volunteers or cadavers may help in the identification of individuals (Sweet et al., 1997a; Anzai-Kanto et al., 2005; Kenna et al., 2011). However, the application of this approach to an actual criminal case has been reported only once before in forensic literature. Sweet and Shutler (1999) obtained a partial and mixed DNA profile from a bite mark on a body submerged in water. This information was mainly used to screen suspects and contributed, along with other physical evidence, to the resolution of that case.

Here, we have reported a homicide case, wherein a full single-source DNA profile of the perpetrator was obtained from bite marks on the victim, and have discussed the techniques employed, which could be useful in the solving of similar criminal cases in the future.

\section{MATERIAL AND METHODS}

\section{Initial observations}

A middle-aged woman was found dead in her home, lying partially clothed in the supine position on a bed. The arms and legs were in abducted position. No evidence of a fight was observed at the scene. Therefore, consensual sexual activity was surmised between the victim and the perpetrator.

The body was autopsied at the office of the coroner; the autopsy revealed that the victim died from manual strangulation. On the basis of postmortem changes, the postmortem 
interval was estimated to be approximately twelve hours. Finger marks were observed on the neck, and a bite mark was observed on each breast (Figure 1).

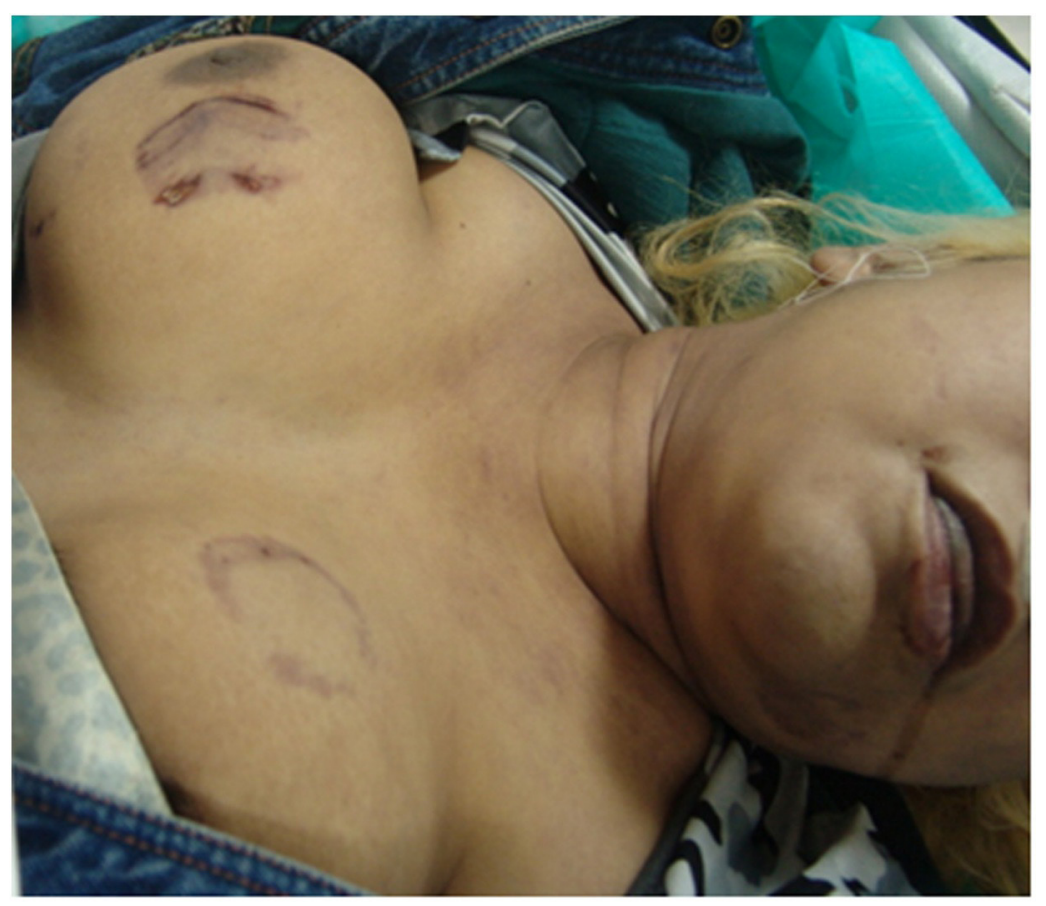

Figure 1. Bite mark injuries on both breasts of the victim. Evidence was collected from the bite marks by the single swab technique, and DNA was isolated from the samples obtained using an organic extraction method. A full single-source STR profile was obtained, which matched the profile of the suspect.

\section{Sample collection}

The bite mark on each breast was swabbed by gently rolling a swab moistened with sterile distilled water on the bite surface. Cervico-vaginal samples were obtained from the body using sterile cotton swabs. All swabs were allowed to air dry at room temperature for 30 min, and were subsequently enclosed in cardboard evidence boxes. Finally, a blood sample was obtained from the victim.

During the course of the investigation, the police identified a man who was the last person to be seen with the victim; this man confessed to being a sexual partner of the victim for some time. Buccal swab samples were obtained from this suspect.

\section{DNA extraction and amplification}

DNA was extracted from the cervico-vaginal samples using a differential extraction procedure, as detailed by Yoshida et al. (1995). DNA was isolated from all other samples using the standard phenol-chloroform extraction and ethanol precipitation (Sambrook and Russel, 2001) methods. 
The DNA extracts obtained from the samples were subjected to polymerase chain reaction (PCR) using the commercially available multiplex kit AmpFLSTR Identifiler (Applied Biosystems, Foster City, CA, USA), according to the manufacturer protocols. This kit simultaneously amplified 15 short tandem repeat (STR) loci, in addition to the Amelogenin gender-determining marker.

\section{Capillary electrophoresis}

The samples were subjected to capillary electrophoresis using an ABI PRISM 310 genetic analyzer (Applied Biosystems). The samples were run on a capillary containing the POP-4 polymer; the Genescan-LIZ 500 standard was used to size alleles, and the data was analyzed using the GeneMapper ID analysis software v.3.2 (Applied Biosystems). STR allele frequency population data (Cerda-Flores et al., 2002; Rubi-Castellanos et al., 2009) and the DNA-View software (Brenner, 2012) were used to calculate the frequency of the genotypes in our population.

\section{RESULTS}

The genetic profiles generated from the samples are summarized in Table 1. A full single-source DNA profile was obtained from each bite mark, which matched the profile of the suspect. Calculation of the genotype frequency in our population provided a value of $6.17 \times 10^{-20}$.

Analysis of the cervico-vaginal swabs revealed that sperm cell (male) fractions resulted in 8 loci, which matched the corresponding loci obtained from the suspect. The calculated genotype frequency in our population was $2.96 \times 10^{-9}$. Epithelial cell (female) fractions rendered a genetic profile identical to that of the victim.

\begin{tabular}{|c|c|c|c|c|}
\hline Loci & Victim & Suspect & Bite marks swabs & Vaginal swabs $^{\mathrm{a}}$ \\
\hline Amelogenin & $\mathrm{XX}$ & $\mathrm{XY}$ & $\mathrm{XY}$ & $\mathrm{XY}$ \\
\hline D8S1179 & $12 / 14$ & $10 / 14$ & $10 / 14$ & $10 / 14$ \\
\hline D21S11 & $29 / 32.2$ & $32.2 / 33.2$ & $32.2 / 33.2$ & $32.2 / 33.2$ \\
\hline D7S820 & $11 / 11$ & $9 / 10$ & $9 / 10$ & $-{ }^{b}$ \\
\hline CSF1PO & $12 / 12$ & $7 / 11$ & $7 / 11$ & - \\
\hline D3S1358 & $14 / 14$ & $15 / 16$ & $15 / 16$ & - \\
\hline TH01 & $6 / 9.3$ & $7 / 9.3$ & $7 / 9.3$ & $7 / 9.3$ \\
\hline D13S317 & $8 / 9$ & $11 / 13$ & $11 / 13$ & - \\
\hline D16S539 & $10 / 11$ & $11 / 11$ & $11 / 11$ & $11 / 11$ \\
\hline D2S1338 & $17 / 19$ & $17 / 23$ & $17 / 23$ & $17 / 23$ \\
\hline D19S433 & $13 / 14$ & $13 / 13.2$ & $13 / 13.2$ & - \\
\hline vWA & $16 / 16$ & $16 / 16$ & $16 / 16$ & $16 / 16$ \\
\hline TPOX & $8 / 11$ & $8 / 8$ & $8 / 8$ & $8 / 8$ \\
\hline D18S51 & $14 / 16$ & $12 / 13$ & $12 / 13$ & $12 / 13$ \\
\hline D5S818 & $9 / 11$ & $11 / 12$ & $11 / 12$ & - \\
\hline FGA & $23 / 26$ & $21 / 21$ & $21 / 21$ & - \\
\hline
\end{tabular}

${ }^{a}$ For simplicity, only the results corresponding to the sperm cell (male) fraction are shown. ${ }^{b}$ No result was obtained.

\section{DISCUSSION}

Bite mark injuries have been observed in some of the most serious crimes, and may often be the only physical evidence available. Saliva has been shown to be recovered, and 
the DNA subsequently typed from bite marks. However, to the best of our knowledge, the application of this approach to an actual criminal case has been reported only once before in forensic literature (Sweet and Shutler, 1999). Therefore, there is limited scientific and technical information available on this subject. In this paper, we have reported the identification of the perpetrator of a homicide through the analysis of DNA isolated from bite marks found on the victim, and have discussed the techniques employed.

Remarkably, a complete STR profile of the perpetrator was obtained. The amount of saliva deposited on the skin is usually very small in bite marks; in addition, environmental factors, such as heat, bacteria, moisture, and mold, can render the DNA unusable (Wick, 2000). Partial profiles were obtained even under controlled experimental conditions, wherein the saliva was placed on the skin of volunteers (Anzai-Kanto et al., 2005).

However, research has revealed that varying qualities and quantities of DNA are extracted from different individuals from the same site, even under similar conditions (Muruganandhan and Sivakumar, 2011). Therefore, the DNA recovered from the evidence may have (by chance) been of sufficient quality and quantity to facilitate STR typing in this case. Furthermore, the time elapsed between the crime and sample collection was approximately $12 \mathrm{~h}$; Kenna et al. (2011) have reported that salivary DNA persists on the skin for a minimum of $96 \mathrm{~h}$.

On the other hand, the good results obtained in this study might have been a consequence of the sampling and DNA extraction techniques employed. Although several techniques, including the use of surgical gauze pads and cigarette papers, have been employed to recover saliva and other trace evidence from the skin with variable success, the use of sterile swabs is the most widely used technique that has received international endorsement. In fact, the double-swab technique is the recommended method for the recovery of dried stains or possible cellular material from the skin (Rogers and Newton, 2000). The DNA collection was maximized by collecting the saliva from the skin surface using two swabs: the first swab was moistened with sterile distilled water, and the second dry swab, used to collect the moisture remaining on the surface after the first swab. These two swabs are subsequently pooled together into a single sample (Sweet et al., 1997b).

Only one swab was used in this study to recover saliva from each breast of the victim; each swab was processed separately. We theorized that this might reduce the risk of obtaining a mixed STR profile of male and female origin, as the less contact with the injuries present on the victim (Figure 1), the less probability of presence of female material in the samples.

Effectively, a single profile, which matched the suspect's profile, was obtained. Previous experimental studies have shown that the double-swab technique allowed for the identification of pure DNA profiles (Sweet et al., 1997a,b; Anzai-Kanto et al., 2005). However, the use of the single swab technique may be more appropriate in actual cases, wherein the skin surface is disrupted and the sample might be contaminated with the DNA of the victim. In addition, despite the use of the single swab technique in this study, the quantity of recovered DNA from the bite marks was sufficient for STR typing. In fact, the difference in the DNA recovering capacity between the single and double swab techniques was only $9.3 \%$ (Sweet et al., 1997b), with such a difference not being significant at least in this case.

Another relevant aspect of this study is the use of an organic extraction method for the isolation of DNA from the breast swabs. A study compared the results of DNA extraction from saliva deposited on human skin among three techniques: organic, classical Chelex, and 
modified Chelex (the latter was considered to be more efficient than the others; however, all methods could be applied for this purpose) (Sweet et al., 1996). Overall, the Chelex methods displayed certain advantages over the organic method, including higher DNA recovery, nonusage of toxic products, and less time-consuming (Lijnen and Willems, 2001). However, in forensic cases, wherein the substrate for analyses is decomposed biological material, the organic method was observed to provide better results than the Chelex method (Hoff-Olsen et al., 1999); in addition, a comparative study comparing the isolation of DNA from saliva deposited on stamps revealed that extraction with an organic technique provides much better results than the Chelex method (Fridez and Coquoz, 1996). Taken together, our results and those of others suggest that organic extraction may be a technique of choice for the analysis of relevant forensic samples with a suspected high level of decomposition (but sufficient DNA for typing).

Sweet and Shutler (1999) also reported a case wherein the single swab technique was used to collect evidence, and an organic method to isolate DNA; however, only a partial and mixed STR profile was obtained in that study. This may have been because the victim was recovered after $5.5 \mathrm{~h}$ from a river with slow-moving current; under such circumstances, the DNA may have undergone a process of degradation, resulting in an incomplete profile. On the other hand, a total of four swabs were taken from the bite mark injury on the victim, and the extracts from individual swabs were pooled into a common exhibit for STR typing, while we used only one swab to recover saliva from each breast of the victim, with each swab being processed separately. This fact supported our assumption that the purity of the DNA profile obtained in this case was a function of the degree of contact between the swab (used for sampling) and the injuries on the victim.

Finally, DNA was isolated from cervico-vaginal samples taken from the victim using a differential extraction procedure. The STR profile obtained for the perpetrator was incomplete. Other techniques may be used for the isolation of DNA in sexual assault cases with variable success, including laser microdissection and flow cytometry. However, a majority of the forensic laboratories use differential DNA extraction, which does not require expensive equipment and can be performed quickly (Vuichard et al., 2011). Also, many factors influence the success of DNA typing in cervico-vaginal samples. Only a partial STR profile may be obtained in case of severe degradation of the genomic DNA, or presence of PCR inhibitors (Butler, 2010). These factors are beyond the control of the investigators, as when possible alternative sources of the DNA of the perpetrator must be considered (the bite marks found on the victim in this case).

In conclusion, this is the second case in forensic literature reporting the analysis of DNA isolated from bite marks present on the victim, in order to identify the perpetrator of a crime. Our results indicate that, contrary to most theoretical indications, a single swab technique for evidence collection and an organic method for DNA isolation could be very useful in solving this class of criminal cases. Saliva deposited on bites must always be considered as a potential source of evidence, especially if DNA cannot be extracted from other sources (difficult or not possible).

\section{Conflicts of interest}

The authors declare no conflict of interest. 


\section{REFERENCES}

Anzai-Kanto E, Hirata MH, Hirata RD, Nunes FD, et al. (2005). DNA extraction from human saliva deposited on skin and its use in forensic identification procedures. Braz. Oral Res. 19: 216-222.

Bowers CM (2006). Problem-based analysis of bitemark misidentifications: the role of DNA. Forensic Sci. Int. 159: S104-S109.

Brenner CH (2012). DNA-View software. Available at [http://dna-view.com/].

Bruce-Chwatt RM (2010). A brief history of forensic odontology since 1775. J. Forensic Leg. Med. 17: 127-130.

Butler JM (2010). Fundamentals of forensic DNA typing. Academic Press, Burlington.

Cerda-Flores RM, Budowle B, Jin L, Barton SA, et al. (2002). Maximum likelihood estimates of admixture in Northeastern Mexico using 13 short tandem repeat loci. Am. J. Hum. Biol. 14: 429-439.

Fridez F and Coquoz R (1996). PCR DNA typing of stamps: evaluation of the DNA extraction. Forensic Sci. Int. 78: 103-110.

Hoff-Olsen P, Mevag B, Staalstrom E, Hovde B, et al. (1999). Extraction of DNA from decomposed human tissue. An evaluation of five extraction methods for short tandem repeat typing. Forensic Sci. Int. 105: 171-183.

Kenna J, Smyth M, McKenna L, Dockery C, et al. (2011). The recovery and persistence of salivary DNA on human skin. J. Forensic Sci. 56: 170-175.

Lijnen I and Willems G (2001). DNA research in forensic dentistry. Methods Find. Exp. Clin. Pharmacol. 23: 511-517.

Muruganandhan J and Sivakumar G (2011). Practical aspects of DNA-based forensic studies in dentistry. J. Forensic Dent. Sci. 3: 38-45.

Pretty IA (2006). The barriers to achieving an evidence base for bitemark analysis. Forensic Sci. Int. 159: S110-120.

Pretty IA (2008). Forensic dentistry: 2. Bitemarks and bite injuries. Dent. Update 35: 48-61.

Rogers D and Newton M (2000). A physician's guide to clinical forensic medicine. In: Sexual assault examination (Stark MM, ed.). Humana Press Inc., New Jersey, 61-126.

Rubi-Castellanos R, Anaya-Palafox M, Mena-Rojas E, Bautista-España D, et al. (2009). Genetic data of 15 autosomal STRs (Identifiler kit) of three Mexican Mestizo population samples from the States of Jalisco (West), Puebla (Center), and Yucatan (Southeast). Forensic Sci. Int. Genet. 3: 71-76.

Saks MJ and Koehler JJ (2005). The coming paradigm shift in forensic identification science. Science 309: 892-895.

Sambrook J and Russel DW (2001). Molecular cloning: a laboratory manual. Cold Spring Harbor Laboratory Press, New York.

Sweet D and Shutler GG (1999). Analysis of salivary DNA evidence from a bite mark on a body submerged in water. $J$. Forensic Sci. 44: 1069-1072.

Sweet D and Pretty IA (2001). A look at forensic dentistry-Part 2: teeth as weapons of violence-identification of bitemark perpetrators. Br. Dent. J. 190: 415-418.

Sweet D, Lorente M, Valenzuela A, Lorente JA, et al. (1996). Increasing DNA extraction yield from saliva stains with a modified Chelex method. Forensic Sci. Int. 83: 167-177.

Sweet D, Lorente JA, Valenzuela A, Lorente M, et al. (1997a). PCR-based DNA typing of saliva stains recovered from human skin. J. Forensic Sci. 42: 447-451.

Sweet D, Lorente M, Lorente JA, Valenzuela A, et al. (1997b). An improved method to recover saliva from human skin: the double swab technique. J. Forensic Sci. 42: 320-322.

Vuichard S, Borer U, Bottinelli M, Cossu C, et al. (2011). Differential DNA extraction of challenging simulated sexualassault samples: a Swiss collaborative study. Investig. Genet. 2: 11.

Wick JM (2000). Don't destroy the evidence! AORN J. 72: 807-836.

Yoshida K, Sekiguchi K, Mizuno N, Kasai K, et al. (1995). The modified method of two-step differential extraction of sperm and vaginal epithelial cell DNA from vaginal fluid mixed with semen. Forensic Sci. Int. 72: 25-33. 